\title{
The Application and Development of Humanities in Physical Education
}

\author{
Ruixue Zhang \\ Information Engineering Department, Guang Zhou South China Business Trade College, Guangzhou, China
}

\section{Email address:}

121503471@qq.com

\section{To cite this article:}

Ruixue Zhang. The Application and Development of Humanities in Physical Education. Science Innovation. Vol. 8, No. 3, 2020, pp. 65-69. doi: $10.11648 /$ j.si.20200803.13

Received: April 20, 2020; Accepted: May 26, 2020; Published: June 8, 2020

\begin{abstract}
The responsibility of physical education teachers is to make students become moral, intellectual and physical all-round development and have a strong body, but in the physical education of various teaching methods of dissent, as well as how to face the experience and lessons of the problem has been long debated, independent. Sometimes in discussing the problem of physical education is like a lump in the throat, the tasteless food, abandon the pity. All kinds of schools at all levels and physical education teaching accident exposure rate most of the "news", the conflict between students and PE teachers, PE teachers and students' parents dispute all the year round, the reason is the requirement for physical education, sports teaching outline with the understanding of physical education of the students and the tests, the entrance examination for students of the physical examination system, the relations between and among points. Therefore, more and more people are calling for humanities to be involved in physical education courses and teaching methods. In order to accelerate the transformation from the teaching mode centered on schools and teachers to the mode centered on people and students, it is necessary to accelerate the development and active application of humanities in physical education.
\end{abstract}

Keywords: Humanities, Physical Education, People Oriented

\section{人文学在体育教学中的应用与发展}

\section{张瑞雪}

广州华南商贸职业学院信息工程系, 广州, 中国

\section{邮箱}

121503471@qq.com

摘要：体育教师的责任之一，是促使学生德、智、体全面发展。教师对体育教学中各种教学方法及经验教训各有主见， 有时在敏感问题上会存在哽咽在喉, 食之无味、弃之可惜的现象。现体育课的“新闻”占各级各类学校教学事故曝光率 不低, 学生与体育教师的冲突、体育教师与学生家长的纠纷时常出现, 其影响因素有体育课程教学大纲对体育课的要 求、学生对体育课的认识、中高考对学生的体育考试加分制度等等。以上现象使得人文学介入体育课程与教学的必要 性和呼声逐渐显现。为加快以学校、教师为核心的教学模式向以人为本、以学生为核心的模式转变, 有必要让人文学 在体育教学中加速发展并寻求积极应用。

关键词: 人文学, 体育教学, 以人为本 


\section{1. 中小学体育教学中常见的问题}

人文学在学校体育教学中的应用已经初步在我国各 级、各类学校实之有行,传统的 " 以体育教师和学校为核 心 " 的教学模式正在逐步转变为 "以学生为核心 " 的模 式[1]。在这样的背景下,以人为本的人文主义教学思想在 体育教育中得到了重视, 但体育教学中以人为本的人文主 义理念发展与应用并不均衡, 部分体育教学中仍然不可避 免的存在“生硬”的教学方法, “我教你学”的现象充斥课 堂。我在收集中小学体育课程与教学素材中选取了较典 型、影响较大的体育教学事故及教师体罚学生事件, 在此 简单叙述如下:

案例1.据滨州日报消息：2019年12月6日下午15时29分 许, 滨州渤海中学北校区初二四班一男生在上体育课期间跑 步呕吐晕倒, 送医急救无效去世。公安机关高度重视并及时 介入, 将在全面调查取证后向学生亲属反馈调查情况[2]。

案例 2.2017 年 12 月 12 日常宁市泉峰中学发生一起学 生意外死亡事件, 常宁市公安局接到报警后迅速赶赴现场 控制相关当事人, 开展现场勘查和调查走访等工作, 并调 取现场视频监控。经核实：2017年12月12日11时23分许, 郭某与李某亮在上体育课期间追逐嬉闹玩要时, 李某亮拿 出所携带的一把棍刀挥舞, 该棍刀从刀鞘中脱离, 击中郭 某的后背。事情发生后, 老师和学校负责人紧急联系 120 到场急救, 郭某经现场抢救无效身亡[3]。

案例3．华西都市报2016年10月26日消息：南充市营 山县涌泉小学一名15岁的初三女学生体育课后死亡。营山 县教育局通过监控调查发现, 死者是与全班同学一起, 慢 步绕篮球场跑 7 圈。学校称, 这7圈总共不到 400 米。下课 后, 学生王蓝 (化名) 便感觉人不舒服之后, 王蓝死亡[4]。

案例4. 邯郸市永年区网信办官方微信号发布永年区 教体局的通报称, 2019年10月31日, 邯䣋市永年区明山学 校六(4)班一名学生在河北省儿童医院不幸死亡。学生家长 反映学生小航（化名）航曾在10月23日的体育课上被体育 教师踢伤, 因而其怀疑小航的死因与此有关。11月3日, 新京报记者从永年区警方处了解到, 踢伤小航的体育教师 薛某已被行政拘留。公安机关已就此事介入调查, 学校已 经要求法医进行鉴定, 有无伤害行为发生等具体问题需等 待相关职能部门调查结果 $[5]$ 。

以上中小学在体育课出现的教学事故及体罚学生现 象至今仍然存在, 体罚过程中造成的学生重伤、轻伤、残 疾都是各界非常不愿意看到的结果。除以上状况外, 体育 教师教学手段简单, 学生的体育精神与趣味体育精神不 足, 使学生对于体育教学产生厌学情绪也属体育教学事故 出现的影响因素。

体育教学方法机械化, 以人为本, 以学生为本的人文 关爱精神的缺失, 将本属于学生释放天性, 激发体育潜能 的体育课演变成了无趣的带有“竞技”性的体育训练课。师 生关系紧张, 互不理解, 学生个体缺乏教师人文关怀, 这 种体育课堂氛围抑制了学生活泼开朗的个性, 阻挡了学生 的个体表现欲望, 使学生极大的降低了对于体育的自信和 兴趣。

鉴于以上情况, 部分体育教师为了避免过多出现教学 事故，在体育教学中又走向了另一个极端，即“不奔跑的
体育课”, 俗称“三无七不教学法”[6]。在上体育课时更有 甚者让学生“带班”, “放羊式”体育课时有发生。这样的教 学方法往个体方面考虑会导致学生身体素质明显下滑, 往 群体方面考虑, 这样的学生走向社会后“弱不禁风”, 缺乏 承担社会责任的精神, 也与体育强国的的精神背道而驰。

基于这些现象, 以人为本的人文学理念在体育教学中 更应该全面推进,对人文学在体育教学中的科学发展与应 用, 体育教学的人文关爱需要与社会环境、家长、学生个 体差异的研究是必不可少的。体育教师需按照职业规范和 要求, 在教学过程中表现出优秀的综合素质, 体育道德、 职业行为、职业意识等诸多职业要求。

作为一名合格的体育教师, 不仅要具备科学的体育教 学方法、更要有高尚的体育道德情操。他们要根据我国目 前体育教学氛围和体育专业教育的特点, 引导学生对体育 课产生认同, 提高学生思想道德品质, 这是当务之急。在 体育教学过程中淡化学校和教师为核心的教学方法, 切实 将应试教育转变为素质教育并落实到教案中去, 培养学生 成为能动的“快乐体育”主体。

\section{2. 影响人文学在体育教学中的发展与应用的客 观原因}

我国体育教师, 特别是中小学体育教师学历普遍较其 他学科偏低, 仍以本科学历为主体。学历在相当的程度上 抑制了本学科教师在一线专业知识和科研能力的提高, 例 如翻译或参考国外体育论著无从下手, 更无法与国际上的 同仁进行学术交流, 不能及时获得国外先进的体育理论。 这也是现在传统常态化的体育教学方法“大有市场”的重 要原因, 以学生为核心的人文精神在教案中体现的不够, 教学手段老化, 在专业教学理论上有排他性倾向。

体育教育学科是一门年轻的学科,尚未形成坚不可摧 的体育教学理论体系, 在我国竞技体育, 金牌至上的大环 境影响下, 建立一个具有人文精神的学校体育教学工程得 不到高度的重视是可以理解的, 这也造成了老师有怨气、 学生有脾气、家长不服气的社会现象。

竞技体育中的高度、距离、速度、时间等客观硬性的 指标, 导致了部分学校的体育课的不合理竞技性, 但这种 竞技体育式的教学带来的回报在一定程度上是显而易见 的。课堂体育教学的教学成果与竞技体育是无法比较的, 以学生为核心的人文关爱的素质教育, 没有客观的硬性指 标, 不稳定因素多。所以人文学在体育教学中的应用与发 展是需要一代代体育人坚持不解的努力去促成的。

体育教学在专业理论上有排他性倾向, 其略微滞后的 教育理论也有些跟不上现在新兴教育理念的更新与创造, 这与本学科专业知识的老化和结构的不合理性, 和现有体 育教师学术水平普遍偏低的现象相互影响, 成为阻碍人文 学在体育教学中应用的重要因素。当前教育系统体制内的 体育教师在接受高等教育期间接受的竞技体育专业教育 普遍要比在体育教学方面要多, 其极端主要现象有两种: 重视竞技体育教学和竞技体育的竞赛规则和轻视现代体 育理论教育及专业体育教师综合素质的培养。以上两种现 
象出现都会导致体育教师在体育教学过程中对“快乐体 育”“趣味体育”的投入不够。

体育课机械单调的动作、教师没有针对性的千篇一律 的说教, 让一节生动活泼的体育课变成了竞技体育课, [7] 使得学生对体育课产生厌倦和反感, 严重的还会导致师生 关系紧张或与教师发生冲突, 学生没有感觉到被重视, 自 己的天分没有激发出来, 这样的体育课实质上是失败的, 没有体现出以人为本、以学生为中心的人文主义精神。

在墨守成规的中小学体育教学中, 体育教师在制定以教 师为核心的教案时, 通常在教案中要求技术动作要在规定的 课时内完成, 制定教案和备课的过程中的以人为本、以学生 为核心的教学价值观体现不出来, 教师在备课及教学的过程 中仍然坚持以应试教育为理念, 体育教学本来应该让学生释 放的天性、在体育课中的“潜能”也没有得到体现。

建议教师可以采用心理暗示的方法, 让学生在心理上 感觉到体育课堂给自己带来的兴奋, 感觉自己能投的更 远、跳的更高、飞的更快, 学生一旦有了这种心理暗示, 体育的潜能将得以更好地发挥出来, 不然会让学生在上体 育课时出现“厌烦”的心理状态。

\section{3. 人文学在体育教学中的应用与发展要落实到 位}

多年来体育教师体罚学生的案例经媒体多次报道都 引起了教育部门及学校、家长、社会各界人士的反响, 多 名专家学者也将此现象作为专项课题进行了学术研究 [8], 较全面的阐述了学校、学生、社会、家长在体育课堂不良 事件中的相互影响, 用大量的数据剖析了不良事件产生的 根本原因和, 并总结了相应的经验教训。

体育课堂中学生对于机械、单调的教学手段感到厌 倦、这刺激了学生对体育课的逆反心理, 当这种不良心理 产生后, 得到的结果往往是学生消极、拖拉、不遵守课堂 秩序, “应付”老师。同时教师的心理也产生了变化, 部分 教师采取强硬的态度来保证教学计划的完成, 这也是导致 体育课堂不良事件的原因之一, 进而出现了非正常的师生 关系。

以课堂教学中体罚为例, 受伤害的往往是学生, 教师 选择惩罚学生的手段也是不明智, 伤害学生的同时也伤害 了教师自己。学生身体的伤害大部分是可以康复的, 但学 生一旦失去了对体育课的爱好及热情这种心理上伤害往 往是不可逆的了。

此时, 必要的人文关怀和人文教学理念的体现在体育 课堂教学中显得尤为重要。在体育教学中转变教学应试教 育理念、改变素质教育中落后的缺乏人文精神的现状、人 文学在体育教学中的体现和教师、学生三者间自然和谐的 发展的研究探讨是当前的重中之重。

\section{4. 独生子女学生群体催生出具有时代特点的体 育课窘境}

上世纪八十年代初期, 我国初中等教育的教学对象产 生了“结构变化”, 独生子女学生群体的时代属性突然出
现。这是因为我国在上世纪 60 年代实行了计划生育的政 策, 在这个背景下出生的独生子女得到了国家、社会、家 庭的关爱, 也存在部分父母不能正确对待独生子女的家庭 教育的现象, 固执的将孩子的不良表现与與论导向推向社 会、学校。到现在我国还没有一个针对独生子女群体的世 界观、人生价值观进行教育的系统教育体系或教材, 没有 针对独生子女群体这一具有强烈时代属性特点的系统教 育工程, 也是大部分家长对于独生子女学生群体的关爱演 变成为毫无节制的宠爱甚至于达到溺爱的程度的现象关 联因素, 对此我简单进行了一些剖析。

独生子女学生群体的“短板”: 在家庭中以“我”为中 心, 大多时候不会顾及家庭成员其他人的想法, 多受娇惯, 饭来张口、衣来伸手, 往往不会顾及家庭的经济能力而经 常向父母提出过分的要求, 比如提出买手机、笔记本电脑 等电器产品的要求, 如父母不同意买, 就大哭大闹、表现 出不达目的誓不罢休的态势。此时大多数父母大会给与满 足要求, 就是这样的厚爱导致了溺爱, 让独生子女学生群 体产生了懒惰而缺乏勤奋, 强调舒适而拒绝吃苦的精神。 现在的家庭条件普遍较好、社会现代化、办学条件优越、 时代发展让独生子女们惟我独尊, 缺乏沟通和协作精神。 在课堂中一旦遇到困难, 会怨天尤人, 遇到责任无担当, 不理解别人、却希望别人多理解自己, 不讲奉献、只讲索 取, 贪图享受的思想比较严重。

独生子女学生群体的鲜明特性: 思想开放、学习及领 会新鲜事物快, 动手能力强, 思维超前, 不计成败, 敢于 坚持自己独到的见解。独生子女在意志特征上的独立性明 显高于非独生子女, 在智力特征上的聪颖性、求知欲望性 和灵活机动性三项理智特征上, 有着鲜明的时代特点及属 性, 大多数独生子女性格开朗活泼, 自信心阈值高, 表现 阈值明显偏高, 他们会经常随同家长四处旅游, 见多识广, 地理、历史知识也相对丰富。独生子女学生群体一旦受到 表彰, 将会极大的刺激其中枢神经的兴奋性, 快速的表现 出对于更高目标的追求特质 [9]。

认识到独生子女学生群体的意志特征及智力特征、时 代特征有助于解读独生学生群体的心理、生理特点。历史 及计划生育国策下的独生子女学生群体特点的不可逆性、 学生时代属性的彰显性、人文学在体育教学中应用与发展 的必要性都向体育教师提出了建立一整套针对独生子女 学生群体的符合时代要求和贯穿人文关爱的教学方法、教 学手段的挑战。

在课堂教学中应既强调体育教学中用人文关爱的教 学理念, 秉持以学生为核心的教学模式, 还要让学生感受 到体育课的愉悦和趣味性、让学生对于体育课有发自内心 的热情, 在此基础上激发学生不同的体育潜能, 释放自身 的能量。

\section{5. 人文学在体育教学中应用与发展的实施策略}

人文学是以研究人为对象、以人为中心的科学, 诠释 了人的信念、理想、人格和价值, 也是利用科学的唯物主 义史观保护美丽、多彩的人生境界的学科, 人文精神体现 在感性和情感, 体现在人生的意义, 充实了想象性和多样 
化的生活。人文教育的核心是人文精神, 人文教育也是人 文精神在教育中的表现手段。

现代人文主义教育从过去的人文主义教育侧重于个 体, 逐步演变为既关心个体, 又关注他人。人文学应用在 体育教学, 其目的就是在教学的过程中发现和培养学生个 体差异性和激发其潜能, 让学生积极主动地参与到体育课 堂中来, 让以往学生被动、消极参加体育课的心理转变为 积极主动地参与。

现代体育教学应是教师和学生的尊严都得到保护, 教 师和学生都相互理解与包容。我们应该结合体育教学的特 点将个性化教育贯穿于整个教学过程, 因材施教地让学生 的人生地位与价值在被他人承认的基础上, 在体育教学中 有所体现, 这样才有助于国家教育教育健康的发展。

我们可以借助我国现行的教育行政管理体制在学校 的管理和导向作用, 对各级各类学校体育课的现状进行客 观的分析, 科学、准确的解读。教育行政管理部门要制定 出一套符合现代学生群体特性的体育教育体系以适应新 时代的变化。

以教学方案的制定为例, 体育教研组应制定既符合体 育教学大纲要求又要符合独生子女学生群体特点的教学 方案, 在做教案时要注意不能强迫学生去完成某项技术动 作或达到一个固定的成绩，去除“为考而教”的观念。慎用 高度、速度、距离、时间等硬性指标去开展体育教育过程 和评价教学效果。在体育教学的过程中要用人文关爱的理 念启发学生对体育课的兴趣, 让学生活泼好动的天性得以 张扬, 不能让学生对于体育课堂感到单调无味, 更不能让 其做机械、枯燥的训练, 防止学生心理产生负面的变化, 让学生不会发出对于体育课兴趣减低的信号。

我们在制定教案时要充分体现出体育教师是直接施 教者和与学生同样都是体育爱好者的精神, 教师要与学生 之间建立良好的互动关系, 不能在课堂情境中出现教师主 动, 学生被动甚至抵触的场面。师生之间有了良好的互动 关系, 师生之间才能互相尊重、互相关爱、互相理解。所 以说原有应试体育教学模式观念改变是必要的, 贯穿了人 文精神的教育理念能更好地被学生理解与接受, 人文学在 体育教学中科学的应用与发展, 能让学生们才能更加热爱 体育课、在体育课中享受速度、高度、距离的美好, 这样 的体育课才是成功的, 坚持这种教学方法有助于让学生们 在身体、生理、心理得到全面的健康成长。

\section{6. 人文学在体育教学中的应用与发展和教师观 念转变互为依托}

体育教师必须加强自身专业学习和主动汲取国内外 最新的教学信息, 学习人文学的有关精神和知识, 例如可 以从加强外语学习能力和注重外语水平发展开始, 提高外 语水平从而在大量的信息中检索适合自身的先进的体育 教学方法及手段。人文教育是一门极其复杂和严谨的科 学, 承载着多学科的理论基础, 我们不是要将每一位体育 教师培养成人文学的专家学者, 而是要倡导人文学, 再简 单一些就是人文精神在体育课堂中的显现与指导意义, 现
在我们要做的第一步就是对体育教师进行人文学的个性 化启蒙, 有意识的将人文因素考虑进课堂教学中。

在体育教学内容设置时要考虑学生生理的差异性, 正 确对待竞技效果, 强化学生的参与性与主动性 [10]。比如 体重较大的学生可以设置推铅球、拔河、或者称手腕等科 目, 体重轻且体形瘦小的学生可以设置蛙跳、钻圈或跳绳 等科目。这样做的目的是能够让同学们根据自身不同的特 点去选择自己喜欢的项目, 当然项目选择绝不是根据生理 决定的, 还要考虑学生的心理, 在心理上产生对体育课的 兴趣是最重要的, 让他们体会到体育课堂的快乐。

\section{7. 结论}

本文基本根据目前我国中小学体育教学的现状, 及影 响人文学在体育教学中的应用与发展的因素进行了简要 分析, 并针对这种现象提出了一些改进的实施策略, 强调 了人文学在体育教学中的应用与发展的必然性。除此之 外, 本文还着重分析了体育课的本质、文化价值、精神意 识、受众群体与体育课的关系, 坚持教学过程中以人为本、 以学生为中心, 注重学生个性化发展, 有意识地代入人文 关怀教学手段与方法。

最后, 真诚的希望人文学能够在体育教学中得到重视 和发展, 这离不开广大从事体育教育同仁的共同探讨和关 注。在新形势下, 希望教育工作者们能够更有承诺、有担 当, 为实现体育强国做出应有的贡献, 增强体育教学的个 性化、兴趣化, 将人文学更客观更科学的应用到体育教学 中去。

\section{参考文献}

[1] 雷城如.体育与健康课程体育教学模式的变革——基于"以 人为本 " 教育观视角 [J]. 南昌师范学院学 报,2012,33(3):94-96.

[2] 吕敏.滨州渤海中学一学生跑步身亡 当地正处理善后事宜 [EB/OL].http://binzhou.iqilu.com/bzminsheng/2019/1208/439 1852.shtml, 2019-12-08/2020-01-01.

[3] 肖舒, 湖南常宁: 泉峰中学一男生玩刀脱鞘 致同学被刺中 后 身

[EB/OL].http://www.hxnews.com/news/gn/shxw/201712/13/1 363042.shtml,2017-12-13/2020-01-01.

[4] 张旭杰.15 岁初三女生体育课后死亡 [EB/OL].https://e.thecover.cn/shtml/hxdsb/20161026/21601.s html,2016-10-26/2020-01-01.

[5] 寇家祥, 张熙廷,邯䣋一小学生“被踢后”身亡, 家属称曾被 班主任指使骗保 [EB/OL].http://www.bjnews.com.cn/news/2019/11/04/645223 .html,2019-11-04/2020-01-01.

[6] 王 宗 平, “三无七不”体育课 [EB/OL].https://m.weibo.cn/2632625191/3863089957476190 , 2015-07-10/2020-01-01. 
[7] 王美娜. 浅谈在体育课中如何激发学生的主动性[J]. 教育界: 基础教育研究,2014,(011):173.

[8] 刘潞琳. 中小学体育教师体罚行为研究[D]. 湖南师范大学.

[9] 全小山,潘运,林伟民.中学生自信发展特点研究[J].保健医学 研究与实践, 2011, 008(003):24-28.
[10] 毛振明.深化体育课程教学改革要正确对待运动技能教学 对 "淡化运动技能教学" 的质疑 [J]. 中国学校体 育,2004,(003):8-9. 